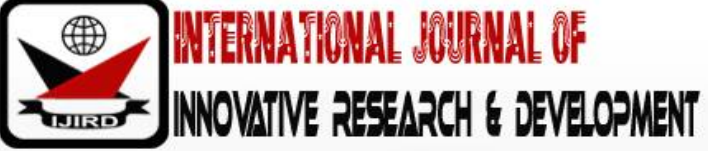

ISSN 2278 - 0211 (Online)

\section{Guji Girja Gada System and Contemporary Challenges}

\author{
Negessa Mokona Tuma \\ Lecturer, Department of Social Anthropology, Bule Hora University, Ethiopia
}

\begin{abstract}
:
The general objective of this study is to investigate the problems presently facing the Guji Gada system. To achieve this objective, qualitative research method was adopted. The data were collected through informal and in-depth interviews, and focus group discussion. The analysis was made qualitatively through explanation and narration. The analysis indicates that problems such as food scarcity and high price of food stuffs, shortage of grass land and rapid population growth, cattle epidemics, bad infrastructure and transportation problem, absence of regular meetings across different gosa/ fira, change in people's way of life from (pastoralism to sedentary agriculture), the involvement of society in trade, education and other paid jobs are internal factors that resulted in to decline of Guji Gada system. Externally, the expansion of different religions in to Guji land and modern form of government by which the Guji are being ruled are factors that negatively affect the Guji Gada system. Some of these factors, on another hand, made the young generation to be indifferent and inconsiderate towards/ of Gada system.
\end{abstract}

Keywords: Gada system, Guji Girja, indigenous knowledge, culture, Ethiopia

\section{Background of the Study}

Before they developed the Gada system, the Oromo had been sharing common cultural, political and religious life with other Cushitic ethnic groups which they used to live together as neighbors (Alemayehu, 2009). It was after the dispersion of these ethnic groups, as the historical records indicate that the Oromo came up with the institution under which they organize themselves systematically. It is a system in which "[a]ll generations enjoy different kinds of power at different stages of the life course" (Asmarom, 2000:128). As Oromo polity is similar to other peoples of Africa, Gada is a democratic system that fits African social structure which the western democracy failed to do so. That is why Asmarom (2000:93) says "democracy is not purely western phenomenon" and Gada is an African version of it invented by the Oromo people.

Gada has its own ways of checking and balancing power. The ultimate power of decision making in Gada system is not vested upon Abbootii Gada but up on the Gumii. Gumii means "the multitude' because it is a very large assembly made up of many councilors (Hayyu) and assemblies (Ya’a) drawn from different sections of the Gada institution, as well as ordinary citizens who have the ability to express their thoughts on matters of national concern, and the interest to travel to (sic) the site of the pre-gumi meetings" (Asmarom, 2000:97). Gumii, by its nature, is so democratic that it allows the participants to evaluate those Lubas on the power. It also revises and evaluates the previously existing rules, modifies them and pass new rules if needed. Therefore, as it is the composition of all concerned individuals from the society, nobody is above what the Gumii decides and attempts to do so even.

There are strong evidences that show the Booran(a) and the GujiGada are almost nearly similar with the original one practiced before the occupation of Oromia by Menilek. With regard to the Gujii Gada system, oral tradition indicates that the Gada came in to existence as a reaction to the maladministration that the Guji experienced under the rule of akkoos and mootiis. Then after, the Gujigada underwent a number of adjustments and modification before it reached the present stage (Dhadacha and Jemjem, 2011:81); however, the Gada of Guji had not escaped the colonial influence even to the extent it was banned not to be publicly practiced. It is after 1991 that the GujiGada has started (Dejene, 2012:113) at least at the level of ritual ceremony if not as the formal administrative organ / ruling system/ under which the Guji decide every aspect of their livelihood as it used to be. Before that time though the government on the power did not allow the Guji to practice Gada, according to Van De Loo (1991:25), Gada was far cry to simple ritual ceremony and "[i]t rather involves blessings, sacred power and exchange of knowledge within the context of the vast Oromo cultural area" as cited in Asebe (2007:118).

The Guji are a confederation of four groups Uraagaa, Maattii, Hookkuu and Alaadduu. The first three groups live adjacent to each other and ruled by common Gumii (GumiiBokkoo). However, Alaadduu live in north-west part of the Guji land in Booran(a) zone around Lake Abbaya and they are ruled by Qaalluu institution where they "adhere to the Qaalluu as the highest court of appeal rather than office of Abba Gada" (Asebe 2007:40). Primarily, in other part of Oromiya in general and the Guji in particular, Qaallicha is the spiritual leader so that he is not supposed to participate in political issues. Even though he did not participate in such case during good old days, the case of Alaadduu is somewhat different from others. 
In short, Gadasystem touches every life aspects of the Oromo people and there is no such influential institution that brings together and unifies the people. This paper presents the status of Gadasystem and the role of present younger generations of Oromiya in general and Guji in particular. It is towards this end that this paper is directed.

\section{General Overview of Gada System}

Several ethnic groups such as Kikuyu, Massai, and Nuer including Oromo people developed 'age and generation system' as social structure in order to keep social orders. According to Nicolas (n.d) age and generation system used "to decrease inter-generational rivalries like competitions about women, cattle, or the exercise of authority" (p, 16). Besides, Baxter and Almagor (1978:159) as cited by Nicolas (n.d:17) say it is "a means of regulating relationships between old and young" and "to create cognitive and structural order within and for a population by creating categories based on age and generation" (p.162). Even though it is one form of age sets, Gadaa "represents an extreme development of social structure" (Asmarom, 1973:50).

He added that nowadays, Gada "is a system of temporal differentiation of society having little to do with age" (ibid). Moreover, Gada has one basic characteristic that makes it different from age sets practiced in north east Africa. That is "--- the newly born infant boy always enters the system of grades exactly forty years behind the father, regardless of the age of the father. Father and son are five grades apart at all times" (P.51). To be precise, Gadaa is not simple system that based on age set and generation set, rather it is very advanced and used to keep every aspect of Oromo society (politics, culture, economic, etc.) in order and guard social justice and safuu (moral and ethical order).

Gada is very broad system that "organizes and orders [the Oromo] society around political, economic, social, cultural, and religious institution" (Asafa, 2010). No matter how, it is very wide institution that touches every aspect of Oromo life, as the scholars in the field of anthropology and sociology who conducted intensive study for a long period of time such as Asmarom Legesse, John Hinnant, Asafa Jalata, and so on indicated the term Gada stands for single Gada grade and ranges to broad socio-political institution. For instance, Asmarom (1973:81) says the term Gada stands for three different things. It is (a) "the concept standing for the whole way of life, (b) any period of eight years during which a class stays in power" and (c) it also "refers to a specific grade (VI) through which every class passes."

Though many writers and researchers wrongly presented it as very complex institution that could not be understood easily, for the Oromo it is very clear and used to govern and protect them and they never found it rigid and incompatible with their way of life. The Gadaa's rules are not strange to the Oromo rather they amend or change if they want to at any time so that every member of the society is governed by it including those who are on power. That is why Asmarom (2000) says" ---the law does not only discipline the highest, it also protects the lowliest" (p.201). Dirribi (2011:197) also stated the fairness of Oromo Gada rule as follows. "Oromo punishes those who violate the law by the law itself, never by the interest of those in power."

Similarly, Verharen (2012) says Gada "--- aims at sustaining peace through its extensive conflict resolution mechanisms such as jaarsummaa, a council of elders dedicated to mediation of disputes" (p.9). Besides, the Gadahas its own principles of checks and balances through which it satisfies the interest of the Oromo people. According to Asafa (n.d) these principles are "periodic transference of power every eight years and division of power---; balanced opposition; and power sharing between higher and lower administrative organs to prevent power from falling in to the hands of despots." Depending on these principles that prove how much the system is democratic, no matter how it is not exactly in the sense of modern concept of democracy, we know in modern western countries, Gada plays the following roles in Oromo society as reported by Dirribi (2011). Gada: makes law, works for the development of country; administers justice, protects national security; settles conflicts peacefully and punishes those who do not accept the settlement; conducts Moggaasa and Guddifacha (adoption); gives political asylum for the refugees who fulfill established criteria; develops and protects the culture, religion etc.) and provides/ assigns someone who helps and protects lonely individuals (pp.277-309).

Though the Oromo institutionalized such organized and systematic mode of government that fits the African social structure and even would be considered as African version of democracy before $16^{\text {th }}$ century, they have not got a chance to preserve and carefully look after it modifying and adjusting it with the newly emerging timely situation because of the coming of the Amara to the Oromo land with the intention of distorting Oromo social structure including Gada system. Because of the absence of modification and necessary adjustment, the following problems are observed in the Gada system according to Asmarom (2000: 256-57).

\section{The Guji Gada System}

\subsection{Who are the Guji?}

The Guji are the branch of Oromo who live in southern Ethiopia in Oromiya and SNNP Regional states. In SNNPR, they live in the areas such as Wondo-Gennet, Nechsar Park, and in Oromiya Regional state they live in Guji and Borana Zones. The Guji speak Afaan Oromoo with their unique dialect, different from other Oromo dialect. As oral traditions indicate, early Guji were pastoralists. Later on, they started to involve themselves in other modes of life like agriculture and trade especially in northern part of the Guji land which is high lead orea. According to Negera cited in Asebe (2007) presently the Guji live in three ecological Zones: below1500m above sea level-Alaadduu who are purely pastoralist; between 1500-2500m- Uraaga some part of Maattii and Hookkuu and the northern [mixed economy] part of Uraagaa and Maattii live in high land areas. In short, nowadays, the Guji are both agriculturalists and pastoralists.

The Guji social structure is somewhat different from other neighboring Oromo groups. Unlike other Oromo groups "Guji is a confederation of four independent, but by no means exclusive, sub-groups known as [Uraagaa Maatii Hookkuu] and [Alaadduu]. The latter is in turn a confederacy of two interdependent groups called [Haloo] and [Weessituu]" (Asebe 
2007:38). The first three (Uraagaa, Maattii and Hookkuu) live adjacent to each other and they are "inter dependent: they regard each other as tied by blood relation, act together in cases of war against neighboring groups, help each other during economic crises, and conduct Gada rituals together" (Tadesse 2012:54). Each of them is divided in to clans which they call fira. There are seven firas under Uraagaa and Hookkuu each and three firas under Maattii. That is why they identify themselves as Gujibalbala torbaa (Maattii used to have seven firas). As it is mentioned above, the three groups of Gujii are ruled by one Gumii (Gumii Bokkoo) under three AbbootiiGadaa. The fira is again divided in to a sub group called mana. The division goes up to single family in which mana is divided in to balbala and in to worra. Marriage system is based on "selfselection and arrangement between families" (Taddesse, 2012:54) even though today self-selection is almost dominating the whole community.

The Guji have their own religion called Mandooyyuu, which is another version of Waaqeffataa, in which they believe in Waaqa ("sky" and "God"). The religious leader is Qaalluu and the political leader is Abbaa Gada. In short, the Gujii are an independent Oromo group with their own indigenous political, cultural and religious system that lead mixed economy and retained their original culture up to the present time.

\subsection{The Origin of Guji Gadaa System}

Oral tradition from Guji society and the research works by anthropologists and authors like John Hinnant (1972), Dhaddacha Gololcha (2006). Tadesse Barisso (2012) Dhadacha Galolcha and Jemjem Udessa (2011), indicate that, the GujiGada system evolved from the attempt made by the Guji society as a response (reaction) to the maladministration the Guji experienced under the administration by individual mootii (king) and akkoo (queen). Before they institutionalized gadaa system, the Guji ruled by five mootiis (Durii Dulloo, Burraaqoo Dooyyoo, Bulee Adalaa, Babaloo Badee, and Baabboo Basuu), then, the era of five akkoos came: Hoyyoyyoo Hoyyoo, Hoyyaa Gaaroyyee, Lalii Lasooyyee, Akkoo Manooyyee. After the era of akkoos, mootii Hiyyoo Kuullee took the power being followed by the joint administration of Annaa Sorraa and Girjaa Biilaa (Dhadacha Gololcha and Jemjem Uddessa, 2011). It was after the above-mentioned joint administration that Gada system was institutionalized (ibid).

The process of changing the administration of individual rulers to the Luba system is present by the same authors as follows. First, in order to settle the problems arisen with regard to the ruling system of the mootiis and the corruption in their administration, a group of wise men called maltuu was formed by the society. Then the maltuu formed yaa'a and over thrown mootii and elected Abbaa Yaa'a who replaced mootii as a leader. Then, the three tribes divided into different subgroups called fira and this formed the Gujifira system. Finally, the maltuu became hayyuu (councilor) and the Guji Gada system came in to existence in the above-mentioned way, and Dhadacha and Jemjem (2011) described the process as follow. "It was said that total composition and enduring stability have been reached through redefining some adjustments and laying down limitations, reassessing the dearth and the depth coupled with cutting the means and measure for them. Therefore, the Guji achievement of the Gada institutionalization was both the product of revolutionary and evolutionary break through to the present form (p.84)."

\subsection{The Guji Gada Classes (Fincaan Shanan)}

In Guji Gada system, Gada classes have different names. They call it 'fincaan shanan' or 'baallii shanan' or 'luba'. In other Oromo groups, especially western Oromo it is called miseensa. (Asmarom, 1973, 2000; Alemayehu 1999; Dhadacha, 2006). All these names refer to the following five classes: Roobalee, Muudana, Harmuufa, Halchiisa and Dhallana.

\subsection{The Gada Grades and the Passage Ceremonies}

The Gadagrades or age-grades, according to Asmarom (2000), refer to "the stages of development through which the groups pass" (p.51). In another word, "it is a conceptual scheme that defines the kind of activities, rights, and duties the groups assume successively throughout their active careers" (ibid:51). In GujiGada system, there are thirteen age grades and these grades can be grouped in to five phases depending on the social and political roles they play in Gada system: childhood phase (Dabballee, Qarree Duraa, Qarree Duubaa); adulthood phase (Raaba, Doorii, Gadaa); retirement phase/ old age phase (three yuubaas: Baatuu, Yuuba, Yuuba Guddaa); extinctive phase (three jaarsaas: Jaarsa Guduruu, Jaarsa Qululluu, Jaarsa Raqeya) and terminal age (Ginya) (John Hinant, 1972). The thirteen age grades of Guji Gada system is summarized below from Asmarom (1973, 2000); Hinant (1973), Dhadacha and Jemjem (2011).

\subsubsection{Dabballee}

This is the first grade in which a newly born male child has to pass through. It is the stage of Abbootii Gada children, who are on the power children at Dabballee stage are considered as girls and their hair style is also feminine which is called guduruu Besides, their dressing style is also the same with girls and they are not allowed to wear pants. The Daballee are treated in especial way and their mothers are privileged in many ways.

\subsubsection{Qarree Duraa / Gaammee Didiqqoo}

This is a stage in which "girls" become "boys" (Asmarom 1973). Even though they have no political obligation to look after the cattle. The privileges they enjoyed at Dabballe stage end at this stage.

\subsubsection{Qarree Duubaa}

At this stage, individuals start to participate in different ceremonies, cattle herding, leading life of adventure (foora), conducting muusoo and they have right of hariirrataa. However, they do not participate in political activities. 


\subsubsection{Kuusa}

This is a transitional stage in which the individuals at this stage go under intensive training offered to them by the Yuubaa. Hence, they are supposed to attend agaalla fooqaa (a training center where they are lectured by the Yuubaa). At this stage, the kuusaa's own formal properties called qarree and bobbasi. According to Jemjem and Dhadacha (2011) kuusa who attend fooqa become the founding officials of the lubaa authority are given the following titles. (1) Faga (two in number) sit infront (2) Abbaa Murtii-sitting next to Faga (3) Jalkeya (Irkisa Abbaa Murrti'ii-assistant of the party) (4) Hayyuu (5) Jaldhaaba (6) Waamura and of the party) and (7) Torbii. It is after this that kuusa will be left free from their father's control.

\subsubsection{Raaba (Senior Warriors)}

People at this stage are responsible for the defense of their people's land, property and life. They undertake didhaa war- a year long journey. An identifying mark, they carry spear with themselves unlike Abbootii Gadaa who carry bokkuu. At this stage, the Raabaas have full economic rights. They receive horooroo' as first implement.

\subsubsection{Doorii}

To be a doorii, the raabaas cut a tree called woddeessa (the event is called Woddeessa Muriisa) and horooroo is replaced by woddeessa. At this stage, the individuals participate in administrative and law-making process. In short, they are the group who are ready to take baallii from their predecessors.

\subsubsection{Gadaa}

This is a critical and the last stage of active phase. It is here where individuals fully take the responsibilities of ruling their people and decide on the issues related to the welfare of their society. It is a very decisive stage that the individuals attempt to show their potential of contributing to the system. Since this stage is very critical, the name of the system (Gada system) and the holder of baallii power) is also called Abbaa Gada'aa (Abbaa Gadoo).

The in effectiveness of the man at this stage would have lasting effect on his respective clan and it determines the future chance of taking Baallii of his clan. If a person commits a fatal mistake that affects the whole Guji society or if his tenure faced any calamity like natural disaster or defeat in a war, it is considered as bad omen (kaayyoo hantuu), so that the clan from which such Abbaa Gada elected way not get a chance to be elected for the kaayyoo of this clan is not good for the whole society. People in the stages after this stage have no separate and distinct roles in the society became, they are in the retirement and extinctive phase.

The individuals in retirement stage are knowledgeable as they accumulate experiences and knowledge through long period of services. Therefore, they "oversee the political and military activities of luba in power" (Asmarom 1987:10). This phase includes Baatuu, Yuuba and YuubaGuddaa. The Baatuu "elevate their sons by the father's personal supervision" whereas the Yuuba take "advisory responsibility and authority on proper performances of ritual activities, and on the interpretation and proper ruling of the law" (p.124). Similarly, the Yuubaa are "retired" and they retain "advisory authority" and "--- they may be required to serve directly in the assembly of the Gada class in power as some of them assistants --- and they are considered as "ritual experts" as well as they are peace maker (s) "(Nicolas, p.4).

The last phase of Guji Gada system is called the extinctive phase which encompasses three jaarsaa s (Jaarsa Guduruu, Jaarsa Qululluu, Jaarsa Raaqeya) and Ginya. The individuals in this stage are supposed to be in the structural senility" and they have "no right to own property but taken care of by their children". As Jaarsa Guduruu and Dabballee have both guduruu, there is similarity between Jaarsa Guduruu and Dabballe: they cannot own property and are looked after by somebody else; the former because of old age and the later because of childhood (Hinnant,1973). This stage is considered as "sacred stage grade and enjoy great respect as ritual leaders".

"In each of the Gada grades, Oromo have their own clearly defined roles and responsibilities to be fulfilled, and there is a system or a ceremony when one passes from one Gada grade to the next" Diribi (2011:213). Similarly, Nicolas (p.6) explains that "The most important transitions between the different grades are marked by rituals, which take the shape of name giving initiation, hand over and retirement ceremonies". The following ones are the passage rites performed in GujiGada system: Maqbaasa, Muusoo, Qarree Buufataa, Bobba'iisa, Baatii haadata/ Yoosittii or Goonaaditti, Woddeessa Muriisa/ Muraa, Hulluuqaa and Dhibaayyuu, Haagana Galchiisa, Dhiiga Qabatiisa, Injicha Keyatiisa, Baallii Kennuu fi Fuudhu.

\subsection{Guji Gada as a form of Government}

Gada as a political institution is a systematically organized form of government. When it is compared with modern form of government system, it has similar structure which is composed of three main political organs: legislative, executive and judiciary. The following discussion is from Dhadacha and Jemjem (2011).

\subsubsection{Legislative}

The legislative form of Guji Gada system has the following structure. At the top, as a legislative body, there Gumii Bokkoo which in turn divided in to three parts following three confederates of Guji groups. The following diagram is taken from Dhadacha and Jemjem (2011). 


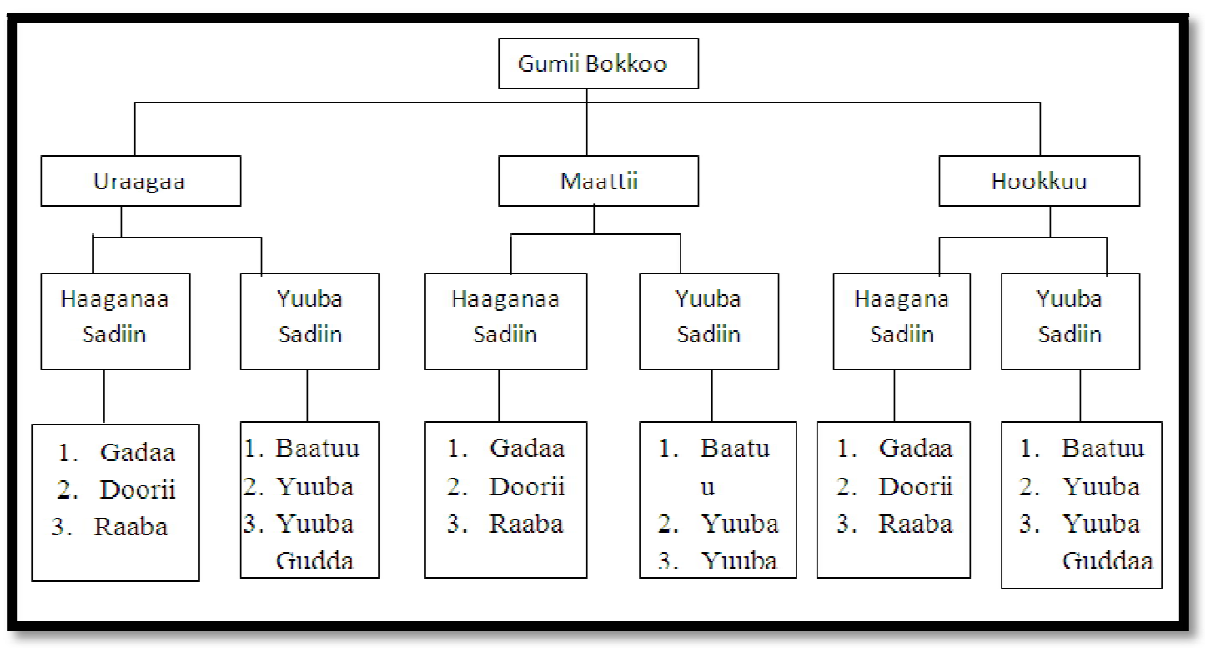

Figure 1

Local luba authorities called Haagana Sagal/ nine senates/ come together at Bokko to make laws and rehearse them. Therefore, Gumii Bokkoo is the only law-making body in Guji Gada system. Similarly, Gumii Bokkoo is the body that makes/ introduces new law, amend and change if needed. When nine senates summit at Bokko and make laws, yuuba sagal / nine councilors/ play an advisory role during law making. Generally, "[a]s legislature, it changes and formulates laws and decisions reached by each Gada" (Jemjem and Dhadacha, 2011:134).

\subsubsection{The Executive}

Gada is a parliamentarian form of government. It has its own mechanism of conflict resolution. According to Asmarom (1973:147) Gada "resolve[s] any type of conflict be it ritual, political, or legal or economic in character." As an executive organ, Gada plays the following roles as it is stated in Dhadacha and Jemjem (2011). It "maintains a form of rational order, the Gada owes the duty of defending its territory and to protect the population.... controls and effects the aiming and proper managing of the entire Gada cycle [and] ... used to impose collection of Woreega - taxation on the members of Yaa'a in cattle, the amount required for rank change ceremonies meant for public purpose".

\subsubsection{The Judiciary}

According to Dhadacha (2006), Dhadacha \& Jemjem (2011) and Hinant (1972), the Gujii judiciary body is composed of Worra, Fira/ Gosa, Yaa'a and Gumii. Therefore, the disputes are entertained first at family level (Worra) in which the heads of family called together. Here, two things must be considered during settling disputes. The elders who address the issue at Worra level should reach the leadership position (Hayyuu) must guide them. This level serves as first instance court. The second level at which the disputes are settled is at Fira/ Gosa level. The trend is similar with the first one. But the elders are summoned from different classes and more than one Hayyuu are needed.

What is not solved at Gosa/ clan level is presented to Abbaa Gada and his counselors which is called Yaa'a. According to Hinnant (1972:184) "the abba gada and his advisors [hayyuu] are the higher court of appeal in the traditional Guji legal system. Any matter which cannot be solved on the local level is brought to him for resolution".

The final decision-making organ/judiciary is Gumii Bokkoo and its "decision may not be reversed... unlike other judicial organs". (Dhadacha and Jemjem, 2011:119). At Gumii "...any individual has the right to attend, to take full part in the deliberation and to bring any matter to the attention of the Gumii"(Asmarom, 1973).Besides, individual person's cases, "...disputes or socio legal matters which arise or pending among different Gada authorities and those which constitute social or general administrative issues are treated and settled by the hayyuus of Gumii Assembly" (Dhadacha and Jemjem, 2011,180).

There are different sayings that express the proper function of Gumii as judiciary organ. The following are taken from Dhadacha and Jemjem (2011). To indicate that hayyuu's refrain from attempting "to deal with the cases before level, the Gujii say "worra gowwaa dubbiin fira dhaxxi; fira gowwaa dubbiin yaa'a dhaxxi". To indicate absence of legal decision repetition they say "korboo teenaan lama hin kaasan", To indicate "the protection of greater interest, it is said 'akka harti gonne, aka raachin dune; muka jiqu jira muka dhibu jira." Finally, through the involvement jadhaaba and selected individuals from clan, "the efficacy of the judiciary lies not only in decision making but also in the mechanism of enforcing them" (Dhadacha and Jemjem, 2011:187).

\section{Contemporary Challenges of Guji Girja Gadaa System}

As oral tradition and many anthropological studies indicated, the Guji had been governed by akkoos (which is referred as bara akko'oo/ era of grand ma's) and mootii (bara mootii/ era of kings) before they institutionalized the Gada system. However, the GujiGada system declined because of some external factors. Van de Loo stated these factors as follows

...the root cause of the decline to the cataclysms of famine and cattle diseases, which united to devastate the Guji and the cattle (1888-1892) accompanied by Emperor Menilek's brutal conquest of the region in 
1984 and the imposition of harsh, crude, oppressive Amhara rule which robbed the Guji of their rights, cattle, and land, all of which 'may have provoked deep change in the Gada system"(Hassen).

Similarly, Hinant (1973), pointed out that the coming of the missionaries to the Gujii land and "the force of "modernity" among the youth who began to question about the advantage and practicality of the Gada system" (p. 41) were the major causes for the decline of the system. Moreover, according to John Hinnant (1977:217), "The decline of gada in Guji as a social institution can be largely explained in terms of factors connected with incorporation in to the Ethiopian Empire. The political and legal leadership has been supplanted by local level Ethiopian administration and national courts." As a result, the whole system was crashed down: the Gada council started to delay handing- over, jump passage ceremony and the society started to refuse to contribute. When they are asked, they made jadhaaba, who tried to force them, to be arrested by police. These all were happened to GujiGada before two or three decades / before 1990s.

However, after the coming of EPDRF to the power with its ethnic- based federalism form of government in which it was promised preserve different ethnic groups culture and identity, as presented by Dejene (2012:119) presents this attempt as follow: "the promotion of the Gada system has been revealed in different, but interrelated aspects. These include the adoption of Gada terminologies and symbols, state sponsorship of the revitalization of various Gada rituals, preservation, promotion of Gada ritual sites, and using traditional mechanisms pertinent to the Gada system in conflict management".

All these attempts have not been down to earth and only made to soothe down the question rose by the Oromo with regard to Gada system. The absence of commitment from the government has been reported by some researchers. For example, according to Tadesse (2012), in the Guji society Gadais reduced to simple ritual system which is not applicable in their daily life as it was.

In addition to what mentioned above, according to the informants, there are both internal and external problems that presently affecting the Guji Gada system. The following are the interviews from the key informants.

The first problem is cattle epidemics. One Yuuba called Bariiso Bilbilo ( 88 years old) reported the problem as follow:

We are facing many problems when we conduct different Gada rituals. There is no enough food like old

times. People are also not contributing like before. So that when we go out from our home, it is not easy

even for us to get what we eat for few days let alone staying for several weeks. Another problem is decrease

in the number of cattle from time to time because of repeated droughts.

With regard to the problem of cattle epidemics, it has been observed especially in Hookkuu and Uraagaa particularly in low land / semi-desert areas. Because of climate change, these areas are highly prone to long season of drought.Therefore, it is difficult for Abbootii Gadaa to celebrate Gadaa ceremonies if the society could not contribute. In relation to this, one Abbaa Gadaa said "Our property and source of our fund is our people but they are becoming very indifferent towards their culture and tradition."

Similar to the above interview one of our informants indicates this problem. "Especially, since the coming of this government to the power, more than three times that the drought stroked our land in which we lost several heads of cattle; as a result, our people could not contribute anything if they lost their cattle".In other words, the whole system of the Gada almost depended on the cattle because it first started to be practiced in pastoralist community, there is no ritual including baallii transfer that performed without slaughtering a cow. Hence, the cattle epidemics directly affect the Gada system.

The second problem is shortage of food. Because of food scarcity which is a result of expensiveness in high price of food stuffs, people stopped to contribute either in cash or in kind when they are asked for the celebration of different rituals. Since the source of fund for rites and rituals celebrated in Gada system is the society, it is impossible for Gada elders to run the system as the previous time. Therefore, this problem is one challenge to the proper function of Gada system.

The third problem is shortage of grass land and rapid population growth. One of our informants reported the problem as follows during FGDs.

Thanks to God that our people are becoming large in number than before. However, our land does not increase with the number of the people. Hence, previously public grass land and wide fields are being occupied by individuals who made them their own property. Those, who are occupying these lands, are youths who do not know the culture and norm of our society. Therefore, they do not allow our yaa'a to settle on those fields with their cattle and there is usually conflict with jadhaabas.

As it can be understood from this interview, one problem as a cause for the decline of Gujii is shortage of grass land and rapid population growth. This shortage of pasture land accompanied by deforestation is resulted in to the depletion in the number of cattle.

Similarly, change in people's way of life has impact on Gada system. For example, land was common property especially in pastoralist community and nobody claim it as private property by fencing as they are doing today so that it was free to move here and there with their cattle and they used to build small temporary huts when they conduct rituals. The change in land tenure system that is from communal to private as a result shortage of pasture land and deforestation resulted in to the depletion in the number of cattle. This has been happened following the transformation of the pastoralism to sedentary agriculture as a country in general and Guji society in particular.

Nowadays all these are impossible because land became private property and enclosed by individuals, let alone to camp on it for two or three months, the Yaa' aas are not allowed to cross even on foot in one's farm or grass land. Here we would like to raise one of such occasion we happened to see. 
It was in 1998 when the yaa'aas were on the journey to Me'ee Bokkoo for baallii transfer, in Uraagaa district Ganda Gaadi'oo , the Yaa'aa came across widegrass land enclosed by fence and they broke in to the compound without getting a permission from the owner for that matter he was not in around, the man came and asked them who allowed them to break in to his farm land and the Jadhaabaas attempted to beat him even for raising such question against Abbootii Yaa'aas. Unfortunately, the man was physically very strong and had beaten up all the Jadhaaba as and chased away their cattle out of his grassland though his family was afraid to help him beating the Jadhaabaas and Yaa'aas as have not heard such a saddening event in Gujii land. The yaa' a as could not do anything even for their Jadhaabaas with bruised head and left the grass land calling a dozen of curses upon the man.

This has been happened following the transformation of the pastoralism to sedentary agriculture in Gujii society. Environmental degradation is also negatively influencing the sustainability of the Gadasystem. Guji culture in general and Gadasystem in particular are highly depend on forests and its products(Negessa 2011). Different Gada rituals have been performed under culturally selected trees (Odaa, qilxaa and etc.). Additionally, forest products like honey are important for makingdrinks (DaadhiiorBooka) to undertake different rituals and ceremonies. Therefore, deforestation and anything that affects the forest has impact on Gada system.

The fourth problem is the society's involvement in to different activities as means of sustaining their livelihood such as trade, education and paid jobs. The following interview indicates this problem.

Previously our people used to bread cattle. Gradually, they started to involve in to farming activities. Others started to run business and go to school. People who do these activities have no time to attentively follow the ceremonies celebrated by Abbootii Gadaa/ Gada elders. For example, those who involve in to farming should look after their farm land; those who run business should go to markets regularly even they go from one country to another country. Similarly, those who go to school regularly follow their education and finally they become government workers. They totally forget our culture and come to watch what we do like foreigners.

With regard to agrarian society (sedentary agriculture) unlike those who breed the cattle, those who engaged in farming cannot leave their farm as they are supposed to look after their crops and the farming itself is seasonal and it is difficult to attend different Gada rituals when they are expected to work on their farm.

Similarly, people who involve themselves in activities such as trade, education and paid jobs have no time to participate in Gada ceremonies and trainings given by the yuubaas at fooqa (a training center for Gada system) because these ceremonies and trainings have their own schedule and principles. If they do not participate on important Gada ceremonies, it is impossible for them to be the part of the system let alone taking leadership post. With regard to participation in Gada rituals, as Alemayehu said ".... participation in the Gada system was a pre-requisite to be a member of a society. Participation was (is) a symbol of belongingness" (p.40) (emphasis added). Those who do not participate, put aside to be included in the system, their Gujooma / Gujiness will be questioned. This is one major cause for exclusion of some groups from taking leadership position in Gadasystem (this point will be explained in detail under section 4.4).

This is resulted in to the isolation of Gadasystem from the sector of education and of politics. By putting it aside, large numbers of people join the above-mentioned activities and finally robbed of their culture. One informant reported this situation as follow:

"Aka waan nama biyya biraatii dhufee, waan nuuti hojjannu- yo nuuti aadaa teenna kabajannu, yo nuuti jila jilannu, yo nu daadimannu, Afaan qabatanii nu daaw'atan. Silaa isaanuu ka nu woliin hojjatanu, ka nu woliin jilatanee nama daaw'achiisanu (when we celebrate our culture, when we worship, when we pray, when we commemorate; they visit us like tourists though they would have been of the actors of the ceremonies).

Bad infrastructure and transportation problems during the journey to Me'ee bokkoo are other problems currently facing Guji gada system. Me'ee bokkoo is the place whereAbbootii Gadaa have been having ceremonies in which they transfer power (Baallii) every 8 years. It is found in Maattii, Bore woreda inGuji Zone. Me'ee Bokkoo is very far for the Gujii clans who live in (Booran zone around Bulee Horaa, Dudda Daawwaa, Sabbaa Boruu; Guji zone, Nageelle, Gooroo Doolaa etc.) Therefore, despite of more access of modern means of transportation than before, distance has been the main barrier for the people who participate on Bokkoo Assembly for there are no good roads that connect different Guji lands to Me'ee Bokkoo. Moreover, absence of infrastructure and means of transportation made the problem even more serious.

Finally, absence of regular meeting across different fira/ gosa is another shortcoming being observed in GujiGada system. For all problems we discussed above there are external factors that exacerbated the situation if not directly at least in directly. One of our informants has put it as follows.

One main factor made our people indifferent towards their culture and Gada system is the coming of different religions to our land. The Guji used to follow Mandooyyuu (their indigenous religion) and this religion was very intact to Gada and our tradition. However, the religions presently our people follow are against Gada system and our culture. The converted people call their previous culture work of devil. They call their previous God, devil and anything we do is what is done for devil. Let alone contributing, they want even to eradicate Gadaa and our culture and attempt to convert us to the religion they follow.

In addition to this interview the elders during FGDs pointed out the impact of different religious denominations. According to their discussion, the expansion of different religions such as Christianity - Orthodox and Protestants with its numerous denominations, Islam and all of them oppose Mandooyyuu the indigenous Guji religion. The influence of different denominations of the protestant Christianity is higher than any other types of religions being followed by Islam. This is because the people who run this religion use Afaan Oromo and there is no clearly defined criterion to recruit the 
converts. Though it offers them freedom of expressing themselves by their own dialects,this religion is very strict towards the Christians involvement in other cultural and social issues that do not promote the religion. Therefore, the informants said that the Protestants are the frightening threat to Gadasystem.

Another external factor that is making the Gada feeble is the modern form of government Oromo in general Guji in particular are being ruled by. Gada is a form of government which cannot be supplementary to federalism or any other form of government; therefore, it is difficult to rule a given society by two different unrelated forms of government. If one becomes stronger and looked after by the society, it is must to wane out for the one which is not looked after by the society. Every structure in Gada system is replaced by modern form of government: Jadhaabaas by police, Abbaa Gadaby zonal and district administrators etc. The disputes are being settled at the court not at the gumiis. Hence that is why the government encourages Gada to be treated as cultural institution and it finally reduced to simple ritual ceremony.

\subsection{Factors Preventing the Young Children from Participating in Gada System}

We have discussed in the previous sections that Gada system requires a lot of things from the individuals before mandating them different social services. For instance, youths at Qarree stage are given regular training at fooqa by the Yuubaa for about 28 days. After that they are required to lead adventurous life (this is made by taking cattle to fooraseveral kilometers away from home). It is after this, an individual entitled as social leader either Abbaa duulaa, or Abbaa murtii or Abbaa gada.

However, nowadays youngsters participate in different governmental and non-governmental issues including politics. There are many things behind this. For one thing, there is no relationship between Gada system and modern form of government by which the Guji are being governed in general and education in particular. Particularly, there is a gap between Gada system and schooling system. For example, children go to school and they have no time to attentively follow the celebration of different rituals and they do not attend necessary trainings. Schools are places where children are socialized and shaped to a certain culture, values and norms the formal education. The educational curriculum and the contents of the subjects of our county are full of foreign experiences and practices and give less attention to the indigenous culture and experiences. Students are educated that foreign culture and their way of life are modern as well as popular whereas the indigenous ones are local as well back warded.

From this we can infer that modern education has impact on Gada system. For that matter an attempt has not been done to reduce this gap. This aggravated the situation and facilitating the ground for the western culture to continue its domination on our culture in general and Gada system in particular. Based on this assumption, we can say that our students do not have time to study their culture in detail, to participate in Gada system and to the have the knowledge about the system teachings as well. Therefore, schooling system laden with foreign culture and values but robbed of indigenous knowledge of the country can be one factor that pushing away young children from participating in Gada system.

On the other hand, similar to modern educational system, different religions are among the factors that are influencing the Gada system. Religions like the Protestants, Orthodox and Muslims are highly expanding in theGuji society and snatching the current generation from their indigenous culture. Therefore, they do not have time to learn and practice and participate in the system. Additionally, these religions are playing great role in changing their mind.

Despite all these, the elders are hopefully prophesying the coming back of the young generation to their indigenous way of life. The following quote indicates this.

"nuuti aadaan teenna hinbaddi jenne hin sodaannu, ta baddu aadaafi amantii aadaa teenna balleessiisaa dhutte tana. Ijoolleen teennalle ifumaan teennaa deebiti.Maarroolleen aadaan ormaa wo isaanii waan hingooneef. Isinille, worruma akkasi dhiisee duri deemettu amma isinii gallaan kuno nu qoraa teessoofi ka'uu nu dhooggitanii motii. (We never think that our culture will vanish rather it is a culture and religion that come to destroy our culture which will vanish. We hope our children will come back to their culture. You (referring to the researchers) your self is one example because you came back when you understand that your culture is valuable.

\section{Conclusions}

This section presents the conclusions of results of data analysis made. Firstly, Gadasystem generally lacks the political, social and economic "weight" it used to have to influence the current generation and policy decisions at different levels. The following reasons should be taken into account. Although there is increasing recognition of Gada system by government, there is inadequate economic or political interest to promote the system interests. As they tend to see it is considered to be a backward/ traditional and unproductive form of political system.

Secondly, although some of the practices are beginning to revive, the whole system remains relatively fragile and scrappy. The major constraint is that it has been difficult for the system to establishing common front with modern government and forging strong institutional links with other groups (modern institutions). Many groups (posts) are led by educated urban elites who although they come from Gada background, they do not necessarily represent the interests of, or report to, local people.

Thirdly, the society itself is highly segregated along wealth, generation and gender lines; variances that are continuously changing in the face of social, political or economic opportunities or restraints. Fresh performers are evolving within the communities that bring different values and welfares. Traditional leaders and institutions no longer have the authority they once had, and in several cases do not certainly represent the interests of ordinary people in the system.

Fourthly, there are both internal and external factors that presently negatively affecting Guji Gada. On one hand, the society's involvement in to different means of sustaining their livelihood such as trade, education and paid jobs. People 
who involve themselves in such activities have no time to participate in Gada ceremonies and trainings given by the Yuubaa at Fooqa (a training center for Gada system) because these ceremonies and trainings have their own schedule and principles. If they do not participate on important Gada ceremonies, it is impossible for them to be the part of the system let alone taking leadership post.

The expansion of different religions such as Christianity - Orthodox and Protestants with its numerous denominations, Islam and all of them oppose Mandooyyuu the indigenous Guji religion in particular and Gada system in general. Therefore, they are living threat to Gada system.

Fifthly, environmental degradation is among the major causes negatively influencing the sustainability of the Gada system.

Oromo have not introduced Gada simply to be governed and known by but used it to give appropriate response to the existing timely situation. That's why their Gada remained original and survived organized and deliberate assault targeted to it.

\section{References}

i. Asafa Jalata (2010) Foundations of a state in Oromiya: Applying Gada principles in the twenty Firstcentury' The Journal of Oromo Studies, Volume 15, Number 2, July: 133-189.

ii. ------- (2009). The Struggle of the Oromoto Preserve and Indigenous Democracy. A Paper Presented on International Conference on Intangible Heritage. 30 May-1June 2009 at university of Tennessee, Knoxville, USA

iii. Asmarom Legesse (1973). Gada: Three approaches to the study of African society. New

iv. York: The Free press

v. -------------- (2000). Oromo Democracy:An Indigenous African Political System. Asmara: The Red sea press.

vi. Alemayehu Haile (2009) Gada System: The politics of Tulama Oromo. Vol. 1. FinfinneeOromia Culture and Turism Bureau.

vii. Asebe Regassa (2007) Ethnicity and Interethnic Relations: The Ethiopian Experiment and the case of the Guji and Gedeo. M.A Thes is submitted to Department ofphilosophy in Indigenous Studies (Unpublished). University of Toromso inNorway.

viii. Dejene Gemechu (2012) Local Response to the Ethiopian Ethnic Based Federalism: Conflictand Conflict Management among the Borana and their Neighbors. Ph Ddissertation submitted to the Department of Social Anthropology (un published)

ix. Dhadacha Gololcha \& Jemjem Uddessa (2006).The Gada democratic pluralism. Addis Ababa: Rela Printing Press.

x. NegessaMokona(2011).Indigenous Forest Management and Utilization System Vs Subsistence Economy. (MA) Thesis submitted to the department of Social Anthropology AAU(Un publication)

xi. Tadesse Berisso (2012) The Riddles of Number Nine in Guji Oromo Culture philosophy in Africa Philosophy Now (Ed Charles C.V and Bekele G.) 